\title{
Identifying Conflicting Routes in Control Table of Indian Railways Interlocking System using NuSMV
}

\author{
K. Sriram \\ SSN College of Engineering \\ Rajiv Gandhi Road, Kalavakkam \\ Chennai
}

\author{
S. Sheerazuddin \\ SSN College of Engineering \\ Rajiv Gandhi Road, Kalavakkam \\ Chennai
}

\begin{abstract}
A "control table" is a functional specification of the signaling system of a railway section. It specifies the routes on which trains are allowed to pass. Control table for interlocking system in Indian Railways is done by a vendor. This control table is verified for correctness by another vendor. The process followed to generate this control table remains a black box, i.e., unknown. Through this paper, a working system has been proposed to explore this unknown process and come up with correct control table entries for a given layout of railway section.
\end{abstract}

\section{General Terms}

Railway Interlocking, Formal Methods

\section{Keywords}

Railway Interlocking, Formal Methods, Model Checking, NuSMV

\section{INTRODUCTION}

A railway station or a railway section is represented as a layout diagram. This layout diagram consists of track segments connected with one another, along with signals, points and level crossings. Signals convey the information regarding operation of train or the track on which the train is set to move, to the driver. Points are the intersection of two track segments. It is used to turn a moving train from one track line to another track line. Level Crossings are the control gates that co-ordinate the movement between road transport and railway without collision.

A "control table" is a functional specification of the signaling system of a railway section. It specifies the routes on which trains are allowed to pass. An interlocking system implements this control table making sure that the running of trains is safe, i.e., without collision and derailment.

Control table for interlocking system in Indian Railways is done by a vendor. This control table is verified for correctness by another vendor. The process followed to generate this control table entries remains a black box, i.e., unknown.

Through this paper, a formal method based working system is proposed to explore this unknown process and come up with correct control table for a given layout of railway section. NuSMV, a model checking tool developed by CMU, is used to generate entries in the control table thereby ensuring the correctness of entries. This paper reports the initial results of research undertaken. The verification of interlocking system being used in Indian Railways is proposed to follow it up.

The paper is structured as follows. The next section describes the related work done in the field of application of formal methods to generation and verification of control table for various railway systems across many countries. In the third section, a very brief introduction to railways and its interlocking system is given. Section 4 describes the research undertaken with a case study in great detail. The paper ends with a concluding section.

\section{RELATED WORK}

There have been many attempts to apply formal methods to railways and their associated interlocking systems. Indeed, this is the subject of the TRain Grand Challenge [1] proposed by Dines Bjorner.

In [8], the authors use SAT-based technique to verify interlocking system of Westinghouse Rail Systems, UK. They implement a prototype that takes as input: the interlocking system (defined using ladder logic); a model of the railway section, and a signaling principle; if a counter-example is identified, the system provides a LATEX document detailing the state of the interlocking system when the counter-example appears. They have also defined a formal language in which one can precisely represent signaling principles. The safety conditions over which ladder logic-based interlocking system is to be verified are derived from these signaling principles.

In [12], the author uses CSP [3] to model the Queensland railway interlocking system. This formal model is checked against the safety requirements, derived from the signaling principles, using the corresponding model checker FDR [6].

In [13], Winter et. al., describe an automated tool for design and verification of control tables. The semantics of control table is modeled by means of the formal notation ASM (Abstract State Machines) [2], developed by Yuri Gurevich, which is easier to read and understand. The formal model is automatically transformed into NuSMV code using the tool support developed by Del Castillo and Winter [4]. The safety requirements to be checked are modeled in CTL [5], the temporal logic supported by NuSMV. They also propose many optimizations to the ASM model to improve efficiency of the model checking process. Further, they provide a procedure for decomposing large interlocking systems into smaller ones, which along with model optimizations makes model checking feasible for realistic case studies.

The work [9], describes a preliminary toolset for automatic generation and verification of control tables for Iranian Railways. In this paper, the semantics of control table is formally modeled as state machines and the safety properties are verified, as usual, using NuSMV tool.

In [7], the authors describe experiments in model checking safety properties of interlocking system of Czech Railways. They use three different tools, NuSMV, Lesar and Mocha. Also, they automatically extract test sequences for the interlocking system using the counter example generation mechanism of these model checking tools. 
In [11], the control tables for State Railway of Thailand are modeled using Colored Petri Nets (CPN). The CPN model comprises of two components namely Signaling Layout Model and Interlocking Model. ML functions are used on arc inscription in the Interlocking Model. These ML functions are generated directly from the content of control table using Extensible Style sheet Language Transformations (XSLT). CPN Tools are used to check safety properties via a state space search.

The work [10], describes the use of formal methods for modeling interlocking systems in Turkish Railways. They discuss how automata and petri nets can be used to model the design of safety critical interlocking software which is a part of Turkish National Railway Signalization Project.

\section{RAILWAYS AND INTERLOCKING}

Railways are split up into railway sections i.e., train stations and depots and open lines connecting the sections. An example railway section is presented in Figure 1. This paper focuses on generating correct control table entries for interlocking system to control a railway section.

A railway section is made up of the following components:

Track Segments: Train lines are split up into segments, and each segment is associated with a track circuit which can detect if a train is on the segment.
Signals: Signals are placed between track segments, and a signal is only visible from one direction. Signals show different aspects; these aspects inform the train driver about the state of the line ahead.

Points: Points are a special type of track segment used to merge two lines into one line. A train can drive over a set of points if it has been locked, i.e. reach a definite position, and has been so locked into position physically and virtually by software. The two possible positions of a point, when it is locked, are called normal and reverse. The normal position is when the point allows a train to move straight over the points and reverse is when the points allows a train to branch off of, or on to, the line. Each point in a railway section is given a unique identifier in addition to the unique track segment identifier. The point ID is given to two track segments where there is a connection between two track lines.

Routes. Routes consist of a sequence of sequentially connected track segments that begin and end at signals, possibly through a set of points. Routes are defined by control table which are created when a railway section is designed. Routes can be set to indicate that a train is using or about to use the route.

Track plans, such as presented in Figure 1, describe how these components are topologically configured. The operation of the various components is defined using control table.

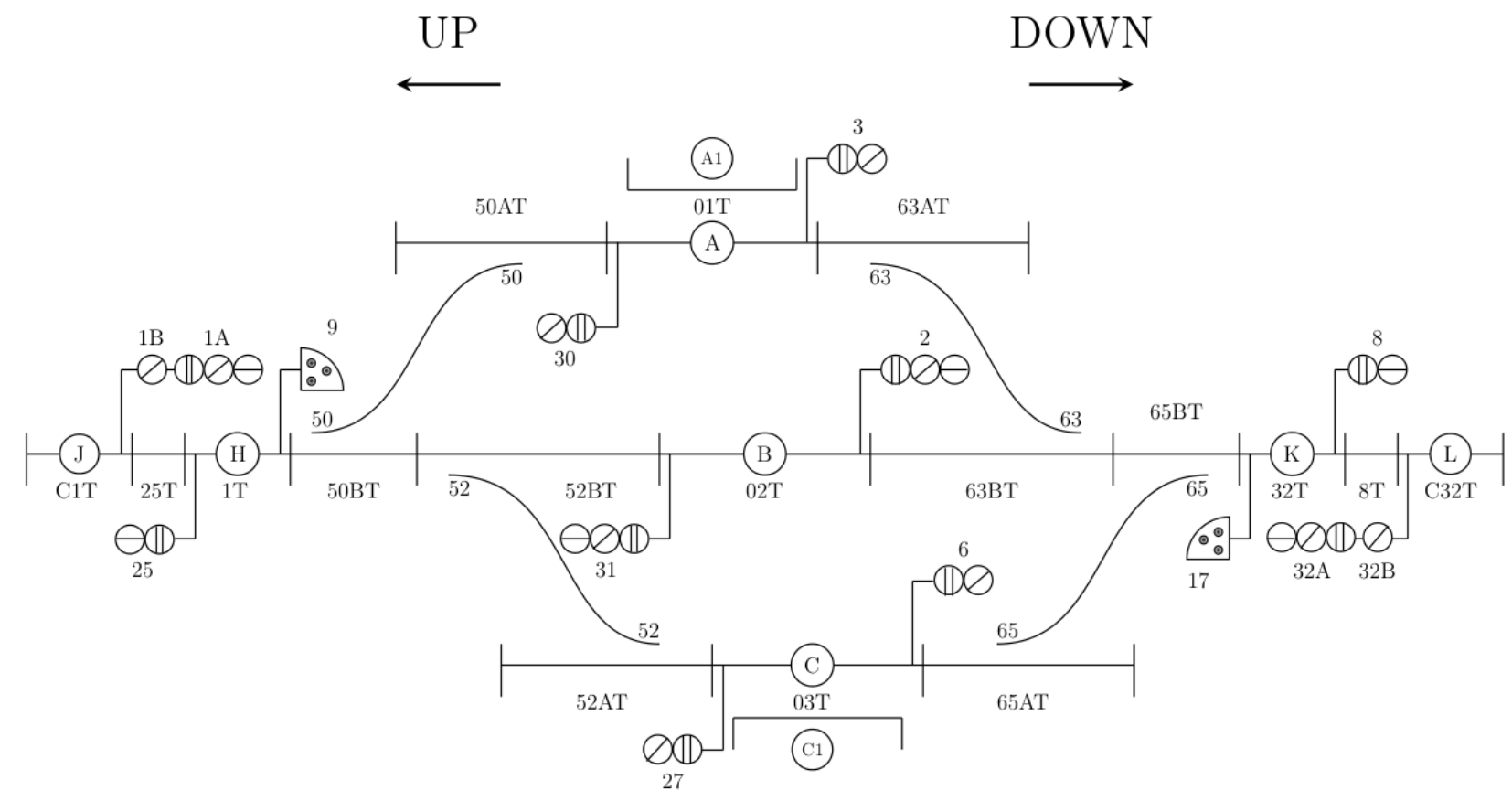

Fig 1: A Railway Section

These contain information about when a route can be set, positions of the points, and the aspect a signal should display. Control table is responsible for enforcing the signaling principles.

Railway interlocking system is designed to implement the constraints in the control table. A partial control table for the given layout is presented in the table 1. Discussion in detail on the above railway section layout and its control table is given in Section 4

\section{IMPLEMENTATION AND CASE STUDY}

In implementing a solution to this problem, understanding the signaling system of Indian Railways requires much importance. The railway section or railway station is represented on a layout. The layout consists of track segments, signals and points. The track segments are segments of track line. A train moves on a track by occupying and releasing a track segment. Signals provide the visually encoded information for the train drivers. They specify 
information like the speed at which the train must move, track on which the train has been allocated to move. Points are the intersection points of two track segments that help a train to change between track lines. A point can be set as normal or reverse.

Every track segment has a unique ID in a given layout. They may also have one or more labels to be used for specifying route through the railway section. Signals have ID to denote them uniquely. Points also have unique ID to be specified. A route is a sequence of track segments starting from a signal. It also contains details about points concerned with the route, to be whether normal or reverse.

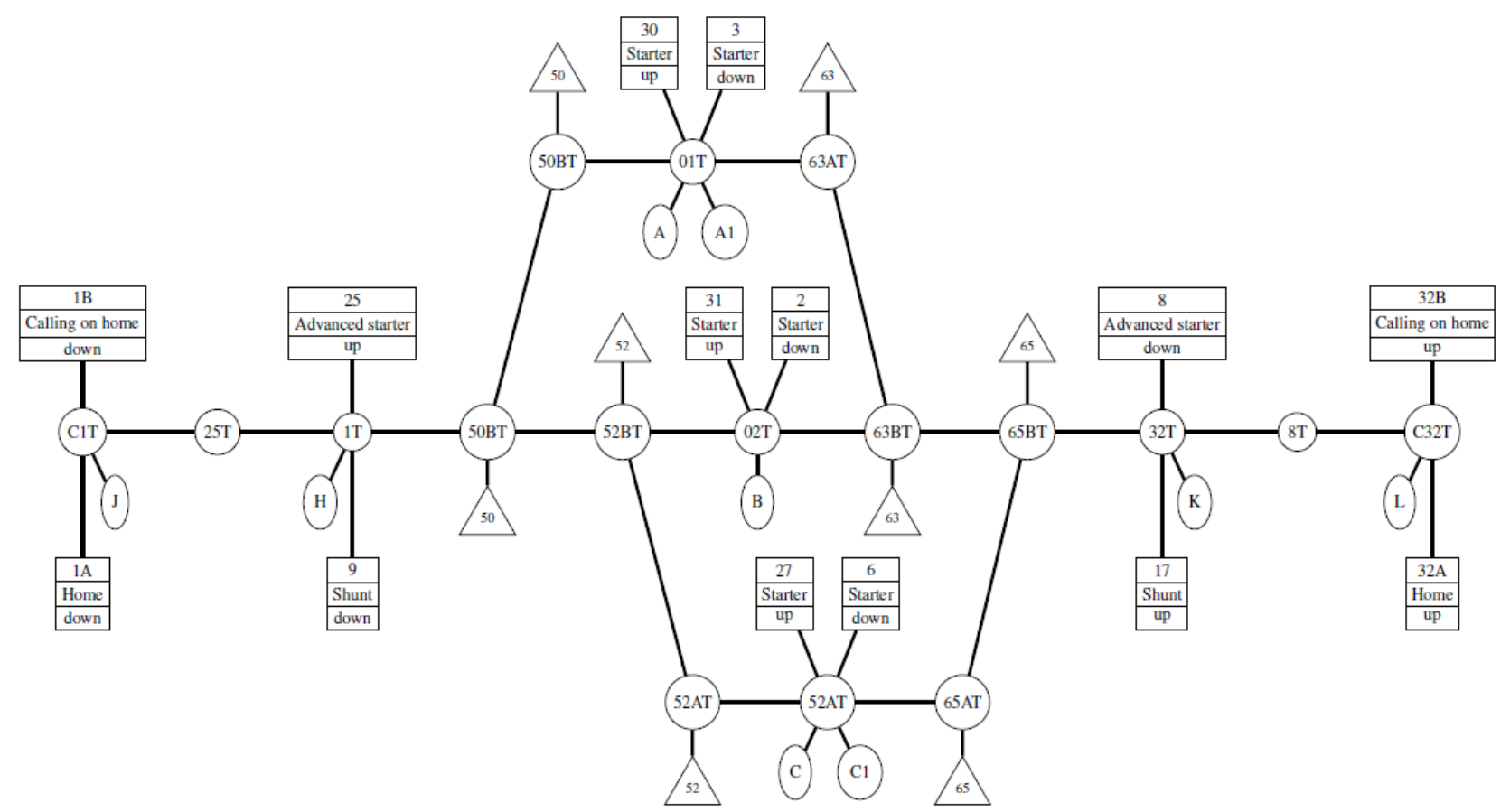

Fig 2: Graph representation of railway section layout in Figure 1

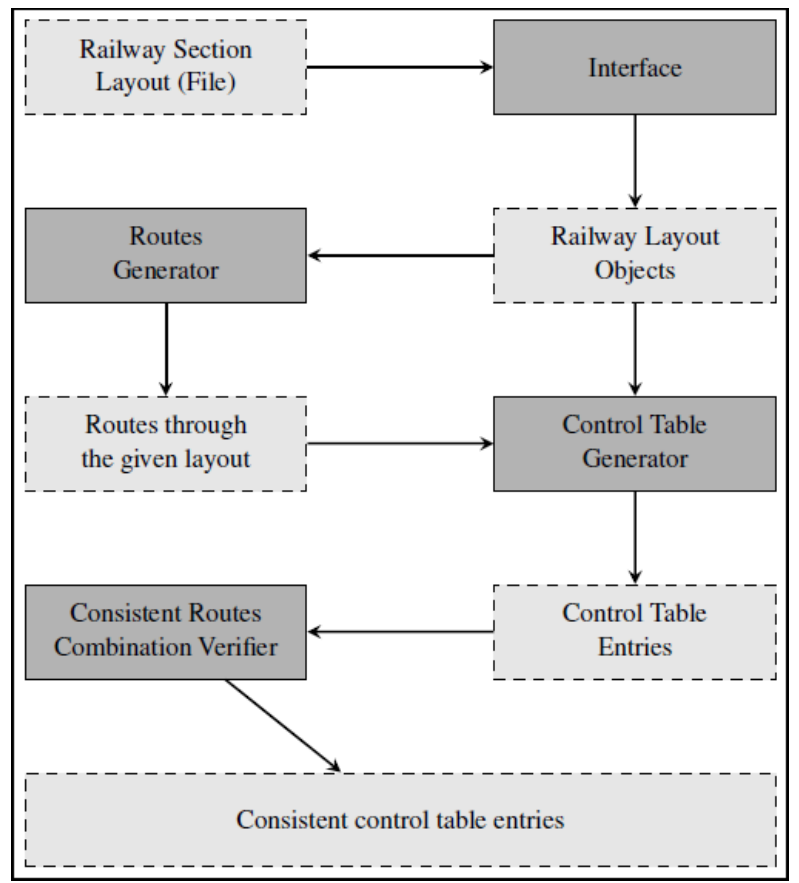

An example railway section layout has been given in Figure 1. In this example, there are two track lines with 17 track segments, 4 points, 14 signals and 9 labels. To give this layout as input, it must be specified using a formal model such as graph. All the labels and ID are specified as attributes of vertices and edges in the graph.

This layout consists of 5 different types of signals namely, calling on home, home, shunt, starter and advanced starter. The 14 signals can be classified into these types. 1B and 32B are calling on home. $1 \mathrm{~A}$ and $32 \mathrm{~A}$ are home. 9 and 17 are shunt. 3, 2, 6, 30, 31 and 27 are starter. 8 and 25 are advanced starter. The starter signals can be further classified into main line starter (2 and 31) and loop line starter (3, 6, 30 and 27). A train can move either towards up or towards down through a railway section. Hence it is important to provide signalling for both the directions.

Fig 3: Project Architecture 


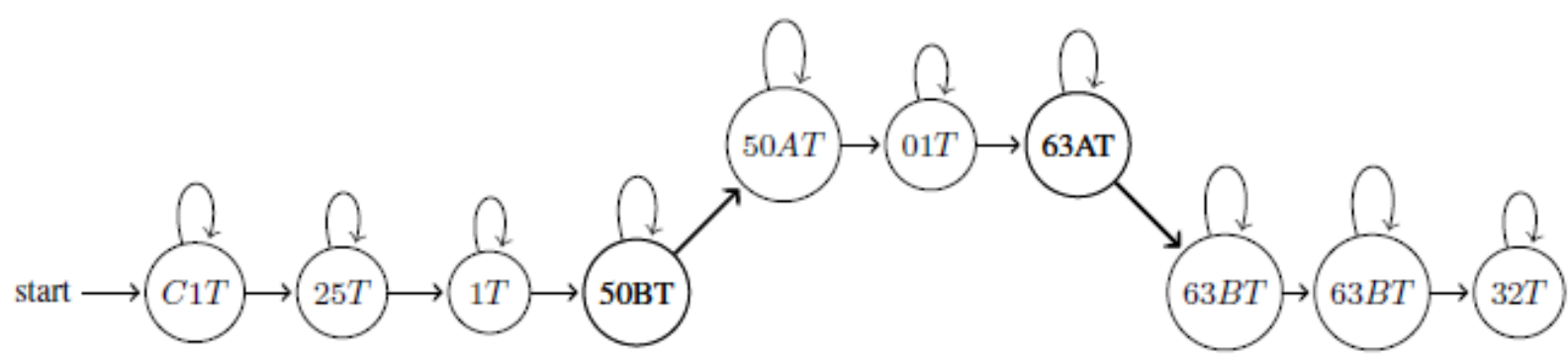

Fig 4: Model of route 1A-A through the Railway Section

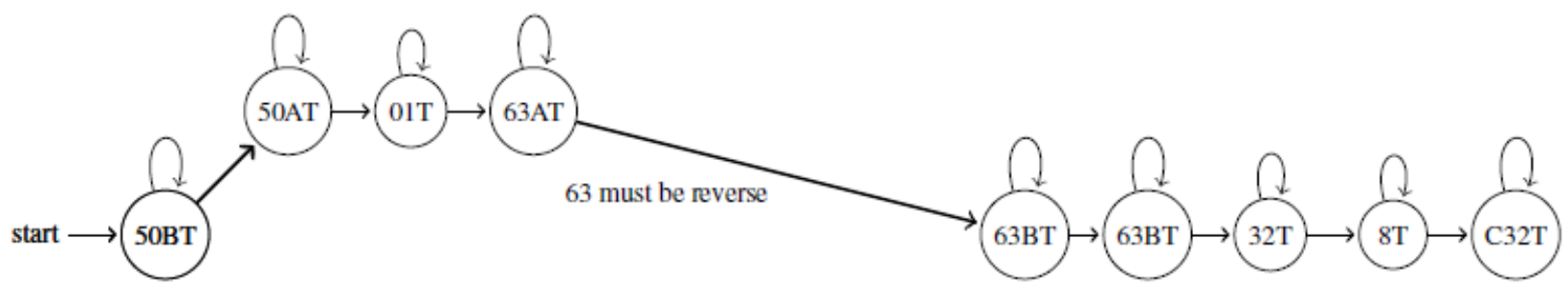

Fig 5: Model of route 9-A through the Railway Section

The points 50,52, 63 and 65 allow a train to move from main line to loop line or vice versa. A main line is the sequence of track segments that can allow a train to move from one railway section to another. A loop line is a sequence of track segments that branches from main line. When calling on home and shunt signal are given to the train driver, he need not stop the train at the specified track segment. The difference between calling on home and shunt signal is, the train moving on calling on home signal will have higher speed than shunt signal. The train following shunt signal will be moving at a very low speed of $10-20 \mathrm{~km} / \mathrm{h}$. Also, for train following shunt signal, there will be a shunter person to monitor the train movement which is not in calling on home.

The above layout is represented as a bidirectional graph to make it easier for program to parse and identify the various aspects of a railway section. The track segments are represented as vertices using circular nodes. An edge connects two vertices if a train can move from one track segment to another. Labels for track segments are represented using elliptical nodes. Signals at a track segment are represented using rectangular nodes. Point IDs for specific track segments are represented using triangular nodes. The graph for above layout is given in Figure 2.

The graph as shown in Figure 2 is represented as text in a file and given as input to the program. The program parses the input file and recognizes the graph in the form of adjacency list. Other information such as signals, point IDs and track labels are also parsed and recognized. The input file consists of 6 sections, each separated by the keyword 'END'.

The first section consists of neighboring vertices where the first vertex on left denotes a track segment on the up side of the railway section with respect to the other track segment. The second section consists of the impossible path that a train cannot take practically at a point.

Table 1: Partial Control Table for Railway Section Layout in Figure 1

\begin{tabular}{|c|c|c|c|c|c|}
\hline $\begin{array}{l}\text { Route } \\
\text { No. }\end{array}$ & Locks \& Detects Points & Locks Routes & Controlled by Tracks & App. Tracks & $\begin{array}{l}\text { Back Lock } \\
\text { Tracks }\end{array}$ \\
\hline $1 \mathrm{~A}-\mathrm{A}$ & $50 \mathrm{R}, 63 \mathrm{R}, 65 \mathrm{~N}$ & $\begin{array}{c}\text { 1B-A, 9-A, } \\
17-\mathrm{A}, 25-\mathrm{J} \\
30-\mathrm{H}, 32 \mathrm{~A}- \\
\mathrm{A}, 32 \mathrm{~B}-\mathrm{A}\end{array}$ & $\begin{array}{c}\text { 25T, 1T, 50BT, 50AT, 01T, } \\
63 \mathrm{AT}, 63 \mathrm{BT}, 65 \mathrm{BT}, 32 \mathrm{~T}\end{array}$ & $120 \mathrm{sec}$ & $\begin{array}{c}\text { 25T, 1T, 50BT, } \\
50 \mathrm{AT}\end{array}$ \\
\hline $1 \mathrm{~A}-\mathrm{A} 1$ & $50 \mathrm{R}, 63 \mathrm{~N}$ & $\begin{array}{c}\text { 1B-A, 9-A, } \\
17-\mathrm{B}, 17-\mathrm{C}, \\
25-\mathrm{J}, 30-\mathrm{H}, \\
32 \mathrm{~B}-\mathrm{B}, 32 \mathrm{~B}- \\
\mathrm{C}\end{array}$ & $\begin{array}{c}\text { 25T, 1T, 50BT, 50AT, 01T, } \\
63 \mathrm{AT}\end{array}$ & $120 \mathrm{sec}$ & $\begin{array}{c}\text { 25T, 1T, 50BT, } \\
50 \mathrm{AT}\end{array}$ \\
\hline $1 \mathrm{~A}-\mathrm{B}$ & $50 \mathrm{~N}, 52 \mathrm{~N}, 63 \mathrm{~N}, 65 \mathrm{~N}$ & $\begin{array}{c}1 \mathrm{~B}-\mathrm{B}, 9-\mathrm{B}, \\
17-\mathrm{B}, 25-\mathrm{J} \\
31-\mathrm{H}, 32 \mathrm{~A}- \\
\mathrm{B}, 32 \mathrm{~B}-\mathrm{B}\end{array}$ & $\begin{array}{c}\text { 25T, 1T, 50BT, 52BT, 02T, } \\
63 \mathrm{BT}, 65 \mathrm{BT}, 32 \mathrm{~T}\end{array}$ & $120 \mathrm{sec}$ & $\begin{array}{c}\text { 25T, 1T, 50BT, } \\
\text { 52BT }\end{array}$ \\
\hline
\end{tabular}

Also, the point ID of a point is given with this info. The third section consists of signal information and the track segment at which it is positioned. The fourth section consists of labels given for track segments. If a label corresponds to platform at which a train must stop, it is given with an extra information '-P'. The fifth section consists of track info of track segments 
to which they belong. The sixth section consists of signal and labels for which the control table needs to be generated. These denote the route end points as the control table will be generated. The input format to be specified in file is given below.

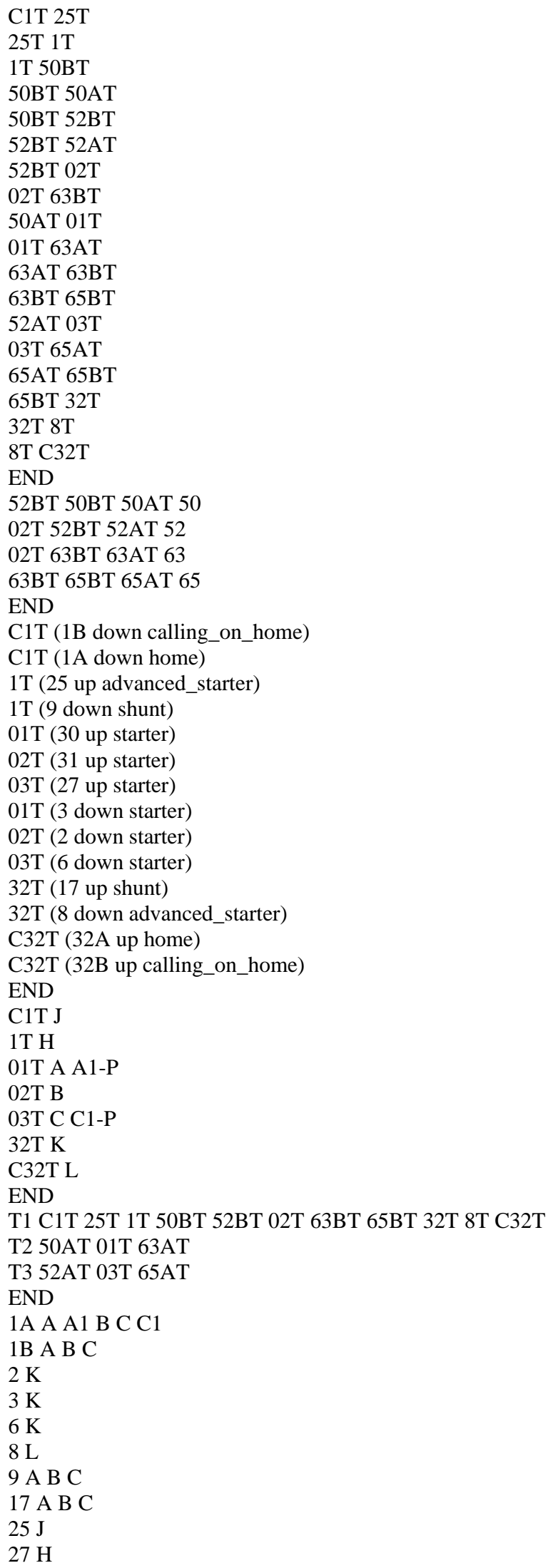

$30 \mathrm{H}$

$31 \mathrm{H}$

32A A A1 B C C1

32B A B C

The program which generates the control table for a given layout is built using Ruby programming language on Ubuntu 14.04 LTS OS. The program follows the architecture as shown in Figure 3. The Routes Generator module makes use of a slightly modified version of Depth First Search algorithm to come up with routes. Control Table Generator module, analyses through the generated routes to find out what must be the status of points for a train to follow the route. The consistent routes combination verifier makes use of NuSMV model checker to verify if two trains following two different routes, will have a collision or not. A basic check must be made to ensure that two routes should not have different status of point, which is common between them. For example, routes $1 \mathrm{~A}-\mathrm{A}$ and $1 \mathrm{~A}-\mathrm{A} 1$ cannot be enabled at same time, as the point 63 is reverse for $1 \mathrm{~A}-\mathrm{A}$ and normal for $1 \mathrm{~A}-\mathrm{A} 1$.

As the trains following calling on home and shunt signals differ from the trains following other signals, there is a need to come up with two different types of models. As an example, build models for 1A-A and 9-A, as shown in Figures 4 and 5 . The point 63 is set to reverse by $1 \mathrm{~A}-\mathrm{A}$ and so the train following 9-A can move till the end. If another route, for example $32 \mathrm{~A}-\mathrm{C} 1$ is considered, it requires the points 52 and 65 to be in normal and reverse respectively, making the train following 9-A route, to stop at 63AT.

This model is represented in NuSMV program. The routes are in the form of modules. They are allowed to move as synchronous non-deterministic transition model from the main module. The condition to be checked for non-collision to ensure safety is given by the below LTL formula, where train 1 is the train following a route and train 22 is the train following a different route.

\section{G !(train_1.track id = train_2.track id)}

In this manner, all the routes are verified for safety and the conflicting routes are identified from the given railway section layout.

The code developed as a solution to this problem can be found in the downloads section of url: http://modelchecking.github.io/identify_conflicting_routes.

\section{CONCLUSION AND FUTURE WORK}

In this paper, it has been shown that a NuSMV program can effectively detect collisions between two routes that can practically be set at a given time. This allows to identify conflicting routes easily for a given railway section layout of Indian Railways as a graph represented in a file. Thus, it is possible to correctly generate control table entries for Indian Railway interlocking systems.

As future work, approach lock and back lock entries, as shown in Table 1 can also be generated for the control table. This can be used to simulate the actual behavior of trains through the given railway section layout verifying for noncollision as safety measure.

The signaling principles that guide the generation of control table entries are currently hardwired in the implementation. Usually, these principles vary with different Railway systems. In fact, they differ even within the zones of Indian Railways. There is a proposal to develop a formal language to describe these signaling principles from the authors of this paper. 


\section{ACKNOWLEDGMENTS}

The authors thank Dr. V. Purnachandra Rao, Chief Engineer (Retd.), Indian Railways Institute of Signal Engineering and Telecommunications, for explaining the intricacies of Indian Railway signaling system and also guiding this research.

\section{REFERENCES}

[1] Dines Bjørner. Train: The railway domain - A "grand challenge" for computing science \& transportation engineering. In Building the Information Society, IFIP 18th World Computer Congress, Topical Sessions, 22-27 August 2004, Toulouse, France, pages 607-611, 2004.

[2] Egon Börger and Robert F. Stärk. Abstract State Machines. A Method for High-Level System Design and Analysis. Springer, 2003.

[3] Stephen D. Brookes, C. A. R. Hoare, and A. W. Roscoe. A theory of communicating sequential processes. $J$. ACM, 31(3):560-599, 1984.

[4] Giuseppe Del Castillo and Kirsten Winter. Model checking support for the ASM high-level language. In Tools and Algorithms for Construction and Analysis of Systems, 6th International Conference, TACAS 2000, Held as Part of the European Joint Conferences on the Theory and Practice of Software, ETAPS 2000, Berlin, Germany, March 25 - April 2, 2000, Proceedings, pages 331-346, 2000.

[5] E. Allen Emerson. Temporal and modal logic. In Handbook of Theoretical Computer Science, Volume B: Formal Models and Sematics (B), pages 995-1072. 1990.

[6] Thomas Gibson-Robinson, Philip J. Armstrong, Alexandre Boulgakov, and A. W. Roscoe. FDR3 - A modern refinement checker for CSP. In Tools and Algorithms for the Construction and Analysis of Systems - 20th International Conference, TACAS 2014, Held as Part of the European Joint Conferences on Theory and Practice of Software, ETAPS 2014, Grenoble, France, April 5-13, 2014. Proceedings, pages 187-201, 2014.
[7] Tomas Hlavaty, Libor Preucil, and Petr Stepan. Case study: Formal specification and verification of railway interlocking system. In 27th EUROMICRO Conference 2001: A Net Odyssey, 4-6 September 2001, Warsaw, Poland, pages 258-263, 2001.

[8] Karim Kanso, Faron Moller, and Anton Setzer. Automated verification of signalling principles in railway interlocking systems. Electr. Notes Theor. Comput. Sci., 250(2):19-31, 2009.

[9] Ahmad Mirabadi and Mohammad Bemani Yazdi. Automatic generation and verification of railway interlocking control tables using fsm and nusmv. In Engineering Modelling 21 (2008) 1-4, pages 57-63, 2008.

[10] Mehmet T. Sylemez, Mustafa S. Durmu, Uur Yldrm, Serhat Trk, and Arcan Sonat. The application of automation theory to railway signalization systems: The case of turkish national railway signalization project. In 18th IFAC World Congress, 2011, Italy, pages 1075210757, 2011.

[11] Somsak Vanit-Anunchai. Experience using coloured petri nets to model railway interlocking tables. In Proceedings $2^{\text {nd }}$ French Singaporean Workshop on Formal Methods and Applications, FSFMA 2014, Singapore, 13th May 2014., pages 17-28, 2014.

[12] K. Winter. Model checking railway interlocking systems. In Computer Science 2002, Twenty-Fifth Australasian Computer Science Conference (ACSC2002), Monash University, Melbourne, Victoria, January/February 2002, pages 303-310, 2002.

[13] KirstenWinter and Neil J. Robinson. Modelling large railway interlockings and model checking small ones. In Computer Science 2003, Twenty-Sixth Australasian Computer Science Conference (ACSC2003), Adelaide, South Australia, February 2003, pages 309-316, 2003. 